\title{
UN SUEÑO DESCONOCIDO
}

Recientemente el profesor Raymond R. MacCurdy, de la Universidad de New Mexico, me invitó para que examinara con él y con el profesor John Longhurst una colección de notas y cuadernos que existía en la biblioteca de don Joaquín Ortega. Durante varios años el profesor Ortega se había dedicado al estudio de las relaciones de Quevedo con el Duque de Osuna, y en distintas bibliotecas europeas había descubierto muchos materiales referentes a ese tema. Entre sus notas, vi una que decía: “Sueños. Casanatense 2269", la cual me interesó en seguida porque vengo preparando una edición de los Sueños a base de los mss. originales. El permiso de utilizar esta cita me fue concedido generosamente, y al recibir de Roma el microfilm, me di cuenta de que el ms. de la Casanatense contenía, entre otras cosas, una copia del Sueño del Juicio final de Quevedo, seguida de otro Sueño totalmente desconocido.

Además de su novedad, este Sueño tiene cierto valor literario. Es una serie de viñetas en que se pintan de manera bastante animada diferentes vicios. El espíritu es agudamente satírico y moralista, y en el lenguaje encontramos el ingenio verbal y la complejidad conceptista que caracterizan la era barroca. El nuevo Sueño plantea, por otra parte, varios graves problemas, el primero de los cuales es el de su atribución a Quevedo. Pero el primer paso para cualquier análisis debe ser la fijación del texto.

He aquí, ante todo, algunos datos bibliográficos. El ms. 2269 de la Biblioteca Casanatense mide $20 \times 14.5 \mathrm{~cm}$., está encuadernado en pergamino y contiene 56 folios numerados, varios de ellos en blanco $\left(1 \mathrm{v}^{0}-9 \mathrm{v}^{0}, 12,4^{8} \mathrm{v}^{0}, 5^{1} \mathrm{v}^{0}-5^{6} \mathrm{v}^{0}\right)^{1}$. Carece de portada, pero en el fol. $1 \mathrm{r}^{\circ}$ aparece una Tabla (que copiaré más adelante). Me parece que los documentos contenidos en el tomo fueron copiados uno tras otro, y por una misma mano. La presencia de los folios en blanco indica quizá que no se copió todo de una vez, o que el copista pensaba intercalar más tarde otras piezas. Aunque no soy paleógrafo, la caligrafía me parece semejante a la de escritos fechados en la primera mitad del siglo xvn. Desde luego, no tiene las características que generalmente se encuentran en la escritura del xvir.

1 Todas mis citas se refieren a la foliación moderna del ms., estampada al pie de los folios. En la parte superior de éstos aparece otra foliación, más antigua y manuscrita, la cual no abarca la Tabla ni las hojas en blanco. 
Antes de la Tabla del fol. $1 \mathrm{r}^{\circ}$ hay una nota que dice: "Este libro es de el Capp. ${ }^{\text {an }}$ Pedro de Medrano". La doble $p$ parece italianismo, al igual que varias otras grafías del ms., y así estoy convencido de que la abreviatura representa Capellán (ital. Cappellano) más bien que Capitán (ital. Capitano). Parece que este Pedro de Medrano (a quien desgraciadamente no he logrado identificar) fue el primer poseedor del ms. Tanto la Tabla como el texto parecen estar copiados por una misma mano, y presentan los mismos italianismos. Una vez en la Tabla y otra en el texto encontramos un error chocante: "duque del Erma" por "duque de Lerma" (se refiere a don Francisco Gómez de Sandoval y Rojas, duque de Lerma y valido de Felipe III) ${ }^{2}$.

Todas las piezas del ms. están en español, y todas, menos una, versan sobre temas españoles. Además de los dos Sueños, hay cinco documentos históricos sobre varios temas tocantes a los años 15481588 , y un Diálogo literario sobre un tema italiano. Los documentos históricos son tres cartas reales para instrucción de ministros o príncipes, una carta con noticias de Lisboa y un papel de Melchor Cano. No se trata, por supuesto, de originales ni de copias oficiales. El volumen parece una colección reunida por alguien que quería poseer documentos históricos y literarios no impresos. La diversidad de temas y fechas indica a su vez diversas fuentes originales, utilizadas sin atención a la cronología (a los dos Sueños sigue la copia de una carta escrita en 1578 ). La pieza más tardía parece ser el Sueño del Juicio final de Quevedo (fols. $34 \mathrm{r}^{0}-38 \mathrm{v}^{\circ}$ ), escrito poco antes de ${ }_{160} 8^{3}$; tras él sigue inmediatamente el nuevo Sueño, en los fols. $3^{8} \mathrm{r}^{\circ}$ $-42 \mathrm{r}^{\circ}\left(\right.$ olim $\left.34 \mathrm{~V}^{\circ}-38 \mathrm{r}^{\circ}\right)$.

El ms. de la Casanatense es una obra sencilla y sin adornos. El texto no está copiado con caligrafía cuidada ni decorativa, y no hay letras doradas ni ornamentación de ninguna especie ${ }^{4}$. Estas caracte rísticas se encuentran en varios mss. de los Sueños de Quevedo, muchos de los cuales son anteriores a la primera edición $(1627)^{5}$.

2 La directora de la Biblioteca Casanatense, señora Pierina Fontana (a quien agradezco muy cordialmente sus informes), me dice que no se sabe nada sobre la procedencia del ms. 2263. Al pie del fol. $4 \mathrm{r}^{\circ}$ hay un sello con las letras "H.C.C.", que yo había tomado por las iniciales de un poseedor antiguo; la señora Fontana me explica que es el sello de Hieronymus Cardinalis Casanatensis, fundador de la Biblioteca.

3 En el Sueño del Infierno, cuya dedicatoria está firmada el 3 de mayo de 1608 , se refiere Quevedo al Juicio y al Alguacil endemoniado. A su vez, en el Alguacil cita el Juicio. (C.. Obras en prosa, ed. L. Astrana Marín, Madrid, 1945, pp. 197a, 202a, 203a).

* Como ejemplos de manuscritos del siglo xvir artísticamente ejecutados, puedo mencionar el de los Sueños que se conserva en el British Museum (MS Additional 26.867) y el de la Politica de Dios existente en la Bibliothèque de la Ville de Rouen (Ms. Leber 894[3094]).

5 Después de 1627 , el interés por tales copias debió de ser mucho menor. Los dos mss. mencionados en la nota 4 se copiaron de impresos. 
El texto del Juicio final que aparece en el ms. de la Casanatense se asemeja por lo general, tanto en sus pequeñas variantes como en sus intercalaciones y omisiones más largas, a la tradición manuscrita de ese Sueño (existen diferencias importantes entre la tradición manuscrita y la de los impresos) $)^{6}$. Parece, pues, que el ms. del nuevo Sueño se copió antes de ${ }_{1} 627$, o sea durante los años en que se hacían muchos otros manuscritos de los Sueños de Quevedo.

Transcribo a continuación el nuevo $S u e \tilde{n} o^{7}$, haciéndolo preceder de la Tabla general del manuscrito, que se halla en el fol. $1 \mathrm{r}^{\circ}$.

Me complazco en expresar aquí mi profundo agradecimiento a los profesores Rafael Lapesa y Raimundo Lida por los atinados juicios que me ofrecieron sobre el texto de este nuevo Sueño.

University of Illinois.

James O. CRosby

- Los datos sobre la tradición manuscrita de los Sueños proceden de algunos estudios míos de próxima publicación.

${ }^{7}$ En mi transcripción del texto modernizo la puntuación, la acentuación, la separación de las palabras y el uso de las mayúsculas. Deshago las abreviaturas, pero pongo en cursiva las letras suplidas. Encierro entre corchetes las letras o palabras que no aparecen en el $\mathrm{ms}$. Al pie de la página, en la primera serie de notas, hago constar las letras del ms. que omito en mi edición. (Reservo la segunda serie de notas para mi interpretación y comentario del texto). No he enmendado los italianismos ni las palabras italianas, y dejo el latín con los hispanismos e italianismos que aparecen en el ms. Siguiendo las normas de la moderna crítica textual, procuro ser lo más parco posible en las enmiendas, y me limito a corregir erratas evidentes. En la redacción de las notas textuales adopto el sistema propuesto para textos del siglo xvir por Ronald B. McKerRow, Prolegomena for the Oxford Shakespeare, Oxford, 1939, empleado ya por FREDSON Bowers en su ejemplar edición de The dramatic works of Thomas Dekker, Cambridge, 1953. El símbolo ] denota la lección del ms., y el símbolo > indica una corrección hecha por el copista. Así, la nota "luan ] Iu. ${ }^{0 "}$ significa que $I u{ }^{\circ}$ es la lección del ms.; y la nota "contiene ] contienen $>$ contiene" significa que el copista escribió primero contienen y luego tachó la $n$ final. 
Este libro es de el Cappellán Pedro de Medrano, en el cual se contiene lo siguiente:

Diálogo a la muerte de Pedro Luiz Farnés [1547] · · · · · · · · · · · · · Institución de el Emperador Carlos $\mathrm{V}$ a su hijo $\left[154^{8}\right]$
Instruición de el rey don Phelipe 2 a sus Presidente y Secretarios $\left[{ }_{15}^{88}\right]$. . . . . . . .

Instruición que dio el rey don Phelipe 2 al Señor don Iuan de Austria su hermano dándole el officio de general de la mar [1578]

Sueño de don Francisco de Queuedo dirijido al duque de Lerma . . . . . . . . . .

Sueño del Juiçio final, dirijido al Cardenal y Arçobispo de Toledo . . . . . . . . .

Carta que escriuió en Lisboa en rrespuesta de otras [1578] . . . . . . . . .

Inperfeciones que escriuió el maestro Cano de oja $1\left[4 \mathrm{r}^{\mathrm{o}}\right]$ oja $9\left[13 \mathrm{r}^{\circ}\right]$ oja $25\left[28 \mathrm{v}^{\circ}\right]$ oja $29\left[32 \mathrm{v}^{0}\right]$ oja $30\left[34 \mathrm{v}^{\circ}\right]$ oja $35\left[3^{8} \mathrm{v}^{\circ}\right]$ oja $3^{8}\left[4^{2} \mathrm{r}^{0}\right]$ sí mismo queriendo su Magestad traerle por confesor [1554].

Dirigido al Illustrissimo y Reverendissimo señor don Vernardo de Rojas y Sandoual, Cardenal y Arcobispo de Toledo.

El sueño, Illustrissimo señor, según Séneca en «Ếrcules 25 furente», en la dicción "Tuque, o domitor somne laborum"

2. contiene ] contienen $>$ contiene

10. Iuan ] Iu. ${ }^{\circ}$

12. Queuedo ] quedo $>$ Quedo (con tilde sobre la $\mathbf{Q})$
13. de Lerma ] del Erma

19. traerle ] traelle $>$ traerle

22. al ] all $>$ al

25. domitor ] dormitor

4. Pongo entre corchetes la fecha de cada documento, sacada (salvo en el caso de los documentos primero y último) del texto mismo del ms.-Pier Luigi Farnese, hijo natural del papa Paulo III y duque de Parma, fue asesinado por sus súbditos en 1547. El Diálogo puede verse en $B A A E E$, t. 36, pp. 1-8; para la fecha, cf. ANGEL González Palencia y Eugenio Mele, Vida y obras de don Diego Hurtado de Mendoza, Madrid, 1942, t. 2, p. 97; t. 3, p. 204.

20. En 1554 Felipe II ofreció el puesto de confesor al maestro Melchor Cano, pero éste lo rehusó cortésmente.

21. Sobre los problemas que plantea el título Sueño del Juiçio final, véase un artículo mío de próxima publicación en $H R$, t. 29 (1961).

22. Bernardo de Sandoval y Rojas fue cardenal y arzobispo de Toledo desde 1599 hasta su muerte en 1618: Véase Rafael Laínez Alcalá, Don Bernardo de Sandoval y Rojas, Salamanca, 1958, y sobre la inversión en el orden de los apellidos (Rojas y Sandoual), el artículo a que me refiero en la nota anterior.

23. El copista escribe Arcobispo sin cedilla (en la Tabla, en cambio, se lee Arçobispo). También falta cedilla en fuerca (lín. 5o) y en torpecas (lin. 281). Sobre esta irregularidad véase lo que dice la profesora BETTY BAYLIss en su edición parcial del manuscrito Suplemento al "Tesoro de la lengua castellana", por Sebastián de Covarrubias (tesis de la Universidad de Illinois, 1959), p. 32, y también mi estudio The sources of the text of Quevedo's "Politica de Dios", New York, 1959, p. 13, nota 1.1. 25. La cita procede efectivamente del Hercules furens de Séneca, vs. Io65-1066. La 
etc., es domador de los trauaxos, sosiego del ánimo, y la mejor parte de la vida, puesto que algunos quieran que no se cuente en ella, llamándole ermano y imagen de la muerte. Dejadas pues sus calidades, y uiniendo a la que haze a mi 30 propósito, según Claudiano en el «6 consulado de Honorio», es famoso rrepresentante que soure el teatro de la noche recita las cosas que de día más se trataron: "Omnia, qua $e$ sensu uoluuntur vota diurno, corpore sopito redit amica quies". Sucedióme al pie de la letra, pues auiendo leýdo antes de 35 acostarme [en] el Catequismo de Pío V, "Inde uenturus es iudicare uiuos e mortuos", soñé de manera que me hallaba en el Juiçio, que me a puesto a punto de perder el crédito sin rrazón: dél me a quedado alguno, valga la verdad. Deste pensamiento y sombras sonnadas podrá ser que despierten

$4^{\mathrm{o}}$ cuydados dormidos "vt veritas magis elucescat".

La confusión de las cossas me pareció al principio que auía buelto a su primero caos, y al fin de toda la desorden, vestida la justiçia de más colores que objetos, la paz fingida y dudosa, la rraçón esclaua, la virtud oprimida, la verdad des-

45 terrada, y finalmente el ceptro de la ambiçión predominante.

[f. $39 \mathrm{r}^{\circ}$ ] Lastimado / desta desorden, que a mi parecer procedía sin rremedio, me saccó de rrepente desta consideraçión la temerosa voz de aquella trompeta final, a cuyos ecos tenblaron los cielos y s'[e]stremeció la tierra, bramó el mar y obedecie-

3o. 6 ] 4

32. quae ] qua'
33. vota diurno ] nota diurna 49. $\mathrm{s}^{\prime}[\mathrm{e}]$ stremeció ] sustremecio

variante laborum no aparece en las fuentes principales del texto de esa tragedia (cf. la ed. anotada de Umberto Moricca, Corpus Scriptorum Latinorum Paravianum, Torimo, 1947, p. 56 ).

27. Es muy conocido el uso de puesto que en el sentido de 'aunque': cf., por ejemplo, M. Romera-Navarro, Registro de lexicografia hispánica, Madrid, 1951, p. 8ogb (cuatro citas); J. CeJAdOR, La lengua de Cervantes, Madrid, 1906, t. 2, pp. $904 b \cdot 90_{5} b$ (seis citas); B. Alemany y Sflfa, Vocabulario de las obras de... Góngora, Madrid, 1930, p. $807 b$ (dos citas); S. Denis, Lexique du théâtre de J. R. de Alarcón, Paris, 1943, p. $57^{6}$ (tres citas) .

3o. En el ms. se lee " 4 consulado", pero el pasaje copiado a continuación se halla en el panegírico De sexto consulatu Honorii Angusti, prefacio, vs. 1-2. Sobre la errata del copista, y sobre la interpretación textual de la cita, véase el artículo a que me refiero en la nota a la lín, 21.

31. soure: léase sobre; hay varios casos análogos: courar (lín. 100, 120), liuro (lín. 159), etc.

33. Según Theodor BirT, en su ed. de Claudi Claudiani Carmina, Berlín, 1892, p. 234, notas, hay un ms. antiguo que contiene la variante errónea nota, la cual coincide con la lección de nuestro ms.; pero en éste es casi seguro que se trata de un simple error de copia (cf. dormitor por domitor en la lín. 25, error debido probablemente a la cercanía de somne). En cuanto a la a de diurna, quizá se deba a una falsa concordancia con nota. En todos los textos de Claudiano que he examinado se lee a continuación pectore, y no corpore; pero como corpore cabe en el sentido general de la cita, prefiero no enmendarlo.

35. La frase "Inde venturus est..." se encuentra en el credo o símbolo de los apóstoles.

40. No he logrado identificar esta cita, si acaso lo es.

49. El original diria probablemente seestremecio, con las dos palabras juntas y 
$5^{\circ}$ ron los infiernos. Grande es la fuerca de la imaginaçión, pues tantas cossas me rrepresentó juntas que no sé si tendré palabras con que rreferirlas. En vn istante pareció con jeneral terremoto abrirse infinitos sepulcros, desacerse promontorios, rrestituyendo la tierra de sus centros los consumidos uesos y

55 oluidadas cenisas de que se formaban los cuerpos ya por tantos siglos acauados, donde si el temor del día diera lugar, no faltaran ocassiones de rrisa en la diferencia de semblantes con que cada vno salía a gozar de su antigua corteza: que era de uer la ferocidad de los Césares y el valor de los capitanes que

60 por solo nombre de fingida fama offrecieron las vidas, arrepentidos tarde de la mala correspondençia que en la otra allaron sus azañas, mostrar las señas y eridas que antes siruieron d'escalones y agora venían por grados de su condenaçión; los auarientos, que a costa de su sangre y las agenas

65 amontonaron riquezas y llegaron tesoros, quán pobres y desnudos venían a ser, juzgados de los pobres a quien desnudaron; los sensuales y glotones, quán ambrientos, y abrasados del maldito fuego de que fueron leña.

$Y$ con ser infinitos, entre todos me causó risa vn portugués

70 tan mal curado en el infierno de su locura, que daua "ao demo" su cuerpo por parecerle muy armado para día tan pacifico y donde forzoso auía de estar su dama; aunque de buena gana vi que trocara con él vn ipócrita, tan pesarosso de perder el crédito de su santidad fingida, que se daua mil 75 vezes por condenado por no serlo vna em público.

Otro ladrón procuraua descartarse de las orejas viendo que se las voluían con las señas de su cortadura, como [si] siendo impresso de las espaldas no estuuiera su istoria de molde.

54. uesos ] cuesos

57. rrisa en ] rrisas $>$ rrisaen

63. d'escalones ] destasones (?)

por grados ] porg. ${ }^{\text {os }}$

65. amontonaron ] amontoñaron

67. sensuales ] sensuase
69. todos me causó risa ] todos me causo me causo risa

71. armado para día tan pacifico ] armadop. ${ }^{a}$ (avmadop.?) dia tanp. ${ }^{\text {co }}$

75. no serlo ] naserla.

76. procuraua ] q. procuraua

78. estuuiera ] estuuieró

con poca abertura de las ees. Cf. infra, nota a la lín. 287 , y en la fotografía del fol. $38 \mathrm{v}^{\circ}$, la forma de las letras $c i$ en las palabras principio y justicia (lín. 17 y 18), o la de $c e$ en sucediome (lín. 10). En mi artículo citado supra, nota a la lín. 21, estudio la posibilidad de que el copista no supiese bien el español.

63. El ms. parece decir destasones, pero la $t$ y la $s$ están borrosas (la $a$, aunque tiene forma extraña, se asemeja a la de christal, lín. 183, y a la última de acompañadas, lín. 175). Quizá el copista confundió la $l$ con la $s$, como hizo en otros dos casos (lín. 67 y 233), y quizá lo que me parece a mi (o le pareció al copista) una $t$, fuera en realidad una $c$ mal hecha. En cuanto al sentido, escalones hace juego con grados; la identidad y la duplicación realzan el contraste entre las acciones que se describen: subir (escalones) y bajar (grados de su condenación).

71. Me parece claro que la abreviatura tanp. ${ }^{c o}$ debe interpretarse tan pacifico, antítesis de muy armado. El chiste, algo oscuro para mí, consiste quizá en el doble sentido de armado, 'provisto de armas' (en contraposición a pacifico) y 'provisto de cuernos', 'cornudo' (con referencia a su dama). 


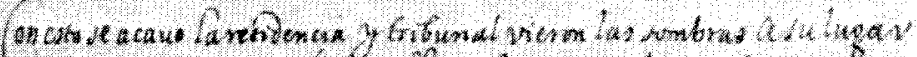

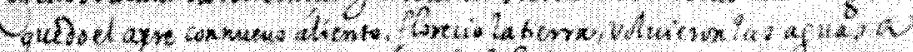

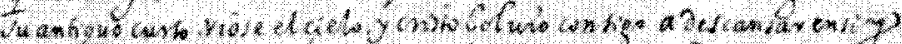

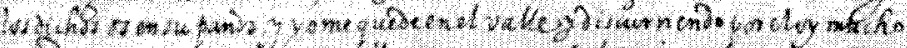

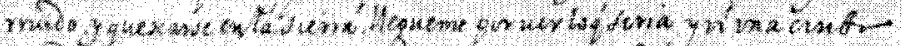

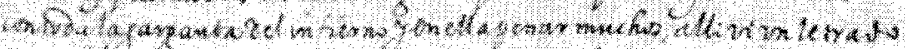

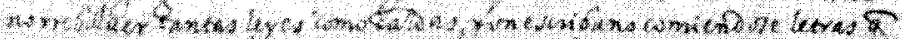

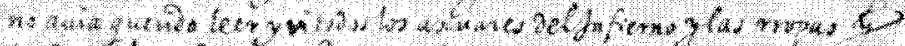

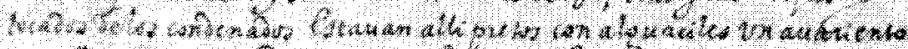

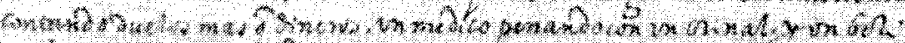

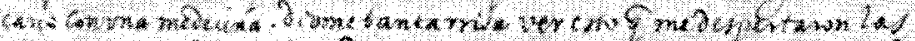

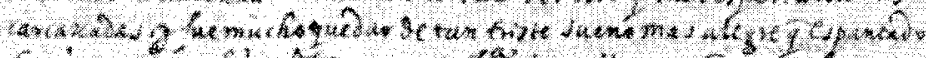

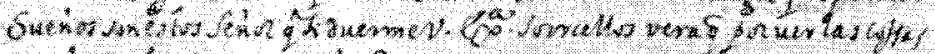

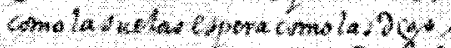

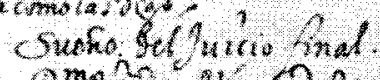

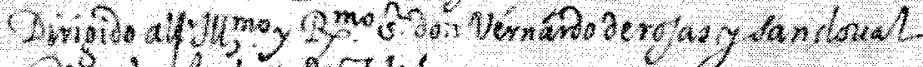

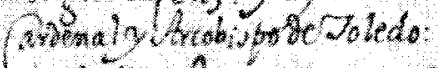

el

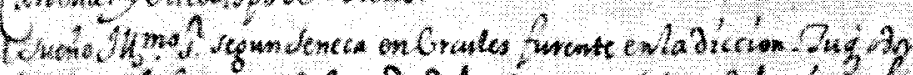

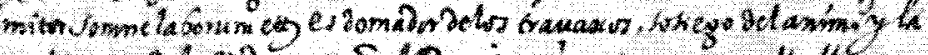

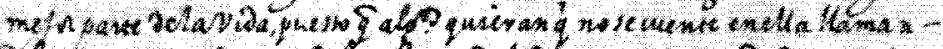

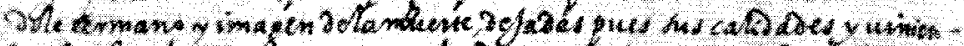

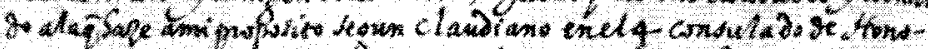

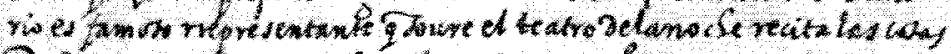

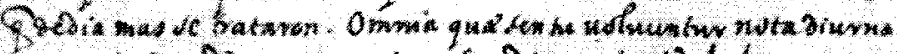

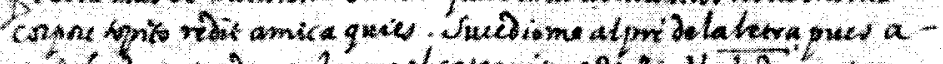

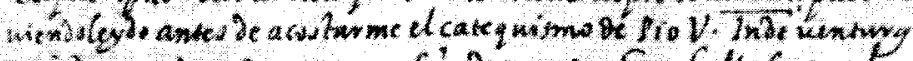

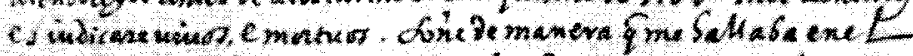

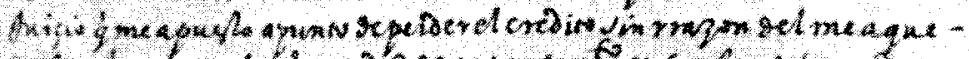

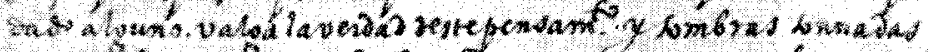

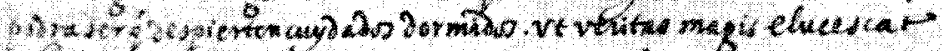

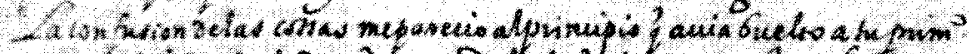

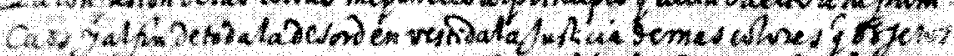

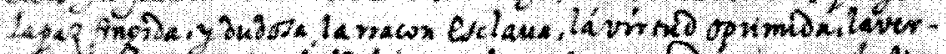

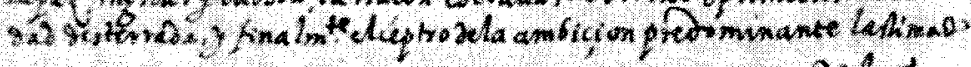
Qs, 10,

Biblioteca Casanatense (Roma), manuscrito 2263, fol. $3^{8} \mathrm{v}^{\text {i }}$ 
De estos primeros objectos me voluieron las vozes de vn

80 bizcaýno a quien venía el alma tan angosta, que persuadido a que se la auían trocado en el infierno, abrazado con vn su ministro decía muy in cólera: "¡Vizcaíno mal conozes! ¡Juras a Dios, diablo la tienes!" A despartir esta quistión acudieron [f. $39 \mathrm{v}^{\circ}$ ] muchos de los $\mid$ nueuamente encarnados, entre los quales con 85 incredible arogançia llegó vn alguacil de los brauos, coleto de ante y perro de ayuda, diçiendo: “†Ténganse a la justiçia, que por vida del Rey que los e de poner a todos en vn calabozo si no parece el alma del señor bizcaíno!" “Harto hará en que no se pierda la suya!", dijo el portero infernal, asido el

9o bizcaíno. A quien él replicó: "Muy poco sentiré esa pérdida, pues por traerla siempre con corchetes, en menores ocassiones me e uisto desalmado".

Vn fhilósopho que acauaua de salir de vn çimenterio de vn espital -común paradero de los tales-, persuadido a que la

95 questión era "de anima", dixo con gran demonstraçión que toda el alma estaua en qualquiera parte, y que se offreçía a probarlo, que la tenía toda en las vñas. "Mal puede ser eso -rreplicó vn sastre oyendo esta proposiçión-, pues por tenerlas yo largas e perdido la mía, de manera que no la espero 100 courar".

A estas vozes y aluoroto fue cosa de ver los escriuanos que acudieron a preuenir la caussa, como si vbiera alguna que poder acriminar. Particularmente vi vno que escriuió en el ayre seys pliegos de papel, examinando testigos cuyos nom-

105 bres no se aliaron en el calendario, tan poco escarmentado de las penas que por semejantes falsedades padecía, como si no pasara por ellas: donde noté la suma prouidençia de Dios, pues en conprobaçión de su bondad y de la rréproba condiçión humana, pienso que tras muchos siglos de tormentos 110 qualquier condenado que voluiese al mundo sería a biuir tan liçençiosamente como si no vbieran salido dél, sin vergüençia de sus culpas ni miedo de sus penas, con que justamente "incidunt in foueam quam fecerunt".

Siempre de un objecto me dibertía la nobedad de otro, 115 como lo fue tras éstos el de vn juez perquisidor, arto perse-

79. vozes ] vezes

81. abrazado ] abrasado $>$ abrazado

91. corchetes ] corcetes $>$ corchetes
97. vก̃as ] vnas

100. courar. ] courarla

102. si] se

85. La forma incredible parece un italianismo más. El copista, a menudo vacilante, escribirá luego increyble (lín. 209).

102. Como sería fácil confundir el italianismo se (= esp. si) con esp. se, enmiendo el texto en este caso.

113. Salmo 7:16: "Et incidit in foveam quam fecit". Cf. también la frase "Qui fodit foveam, incidit in eam" (Proverbios, 26:27; Eclesiastés, 10:8; Eclesiástico, 27:29).

115. La palabra perquisidor no está documentada en el $D C E C$; sin embargo, parece forma tan legítima como el pesquiridor (Rimado de Palacio) y el pesquisidor (Nebrija) que registra Corominas. En todo caso, se puede ver un ejemplo de perquisidor en ANiceto de PAGÉs, Gran diccionario de la lengua castellana, Barcelona, s. a. 
guido de los inocentes condenados que por fuerça le llebauan a dar cuenta en el Juizio del error de los suyos. Y preguntándole la caussa de auer condenado sin ella a los que lo auían de ser de que él lo quedase, respondió que el perquisidor $\left[\mathrm{f} .4 \mathrm{r}^{\circ}\right]$ ha / de entrar quitando vidas sin derecho, con que coure el crédito por después quitar las haziendas.

Persuadíase a otra parte vn ventero que tenía buen pleito en esta ocassión, juzgando que pues las que alli se dauan para justificaçión de los vienauenturados era dar de comer a los

125 hanbrientos y ospedar los peregrinos, él, que auía gastado lo más de sus años en este ministerio, forçoso sería de los de la mano diestra. Mas como azía (como ellos suelen) la cuenta sin los huéspedes, hallóse dos a sus lados tan vuenos contadores, que le boluieron la data por cargo, y pensando alcanzar

130 el çielo quedó deudor del infierno. Mostráronle el rrobo y el engaño, los jumentos conuertidos en ternera, la obeja en carnero, el agua en vino, el gato en liebre, con las demás trasformaçiones con que pasaba su bida, haciendo milagros en los desiertos.

135 Llegáronsele otro infinito número de transformadores, pasteleros, rregatones, despenseros, toda jente que dicen del gordillo, condenados en vida: pues como si no vbiera de tener fin, la passan engañando al mundo. Finalmente era la muchedunbre destos miserables tan infinita que por todas partes al

140 son de la final trompeta de los abismos de la tierra salian, que me pareció imposible conprehenderla, aunque ui que de la manera que el sol sale de sus balcones, lleuando tras sí las sombras que huyen de su luz dorada, assí ante aquel temeroso son todos los nueuamente rresucitados bolauan al valle que

145 a mi pareçer era el de Josafat, donde entre el cielo y la tierra pareció aquel sumptuosíssimo trono, de imensa magestad y sol rrodeado, donde en sí mismo estaba el Verbo encarnado con las señales de su vitoria y muestras de nuestra salud, cercado de serafines y bienauenturados. Tenía el trono por la parte

$15^{\circ}$ inferior, por donde auían de subir los escojidos, vna puerta tan estrecha que los que auían de entrar, por ayunos y macilentos que llegasen, no le podían haçer sin dexar mucho de sí mismos. Eran las dos puertas bautismo y penitencia; tres gradas con que subían, fe, esperanza y caridad; [y] por guarda los

\footnotetext{
117. Juizio ] Juicio $>$ Juizio

119. él lo ] ello

120. quitando ] quedando

131. engaño ] engano
}

138. engañando ] engañado

146. sumptuosíssimo ] sumptuosossimo

15o. escojidos ] escojdos

152. Según Hayward Keniston, The syntax of Castilian prose in the sixteenth century, Chicago, 1937, $\$ 7.33$, "the use of $l e$ as a neuter is extremely rare". Como ninguno de los poquísimos ejemplos aducidos por Keniston es tan claro como el de nuestro texto ("no le podían haçer"), supongo que se trata de una errata cometida por un copista que no sabía bien el español. 
menores por parecello! No ui ninguno que en su estado no uiuiese al rreués de lo que deuía, y sobre todo los miserables

195 pretendientes cargados de memoriales y faltos de memoria, anhelando por comprar voluntades y adquerir fauores, donde

[f. $4^{1} \mathrm{r}^{\circ}$ ] el que $\mid$ más tenía estaría menos satisffecho. Y em particular me acuerdo de uno, tan lastimado de lo que en este purgatorio auía padecido, que deçía se olgaba de estar en parte donde

200 sin hacer rriuerençias ni aguardar consultas le daban la plaça sin pedilla, por solos sus méritos. ¡A cuántos mostraua el desengaño, aunque tarde para su rremedio, por justificaçión de su daño la falsedad en el secretario, el engaño en el juez, la mentira en el valedor, y el desacuerdo de todos y la poca cor-

205 dura suya! Pues entre tantos desengaños no ui ninguno que se tubiese de que no mereçia el fin de su pretensión, y particularmente en materia de prebendas eclesiásticas. Era de manera la desorden entre los príncipes y ministros de la Iglesia a quien esta misma abía condenado, que era lástima increýble, tanto

210 que su primer inuentor, Simón Mago, se quexaba del príncipe de los apóstoles, San Pedro, por hauer tenido con él tanto rigor, quedando libres al parecer los que con mayores obligaciones biuen tan lexos de guardarlas -aunque esta quexa no tubo lugar, porque en este tribunal no se perdonan ni aun los

215 pensamientos, por más que los juristas aleguen que es contrato cuya açión consiste en el echo.

Tras la Ambiçión y Soueruia entró la maldita canalla de Lutero, Mahoma y sus sequaçes, con toda la maldita canalla de hereges y apóstatas que, como indignos de la misericor-

220 dia de Dios, prouocauan contra ellos los çielos y la tierra: blasfemos, perjuros, de las nabaxas de sus lenguas despedazados; los bárbaros ydólatras, semejantes a sus dioses en las culpas y castigos.

Entre los cuales con no pequeña confusión vi los poetas,

225 que con la dulçura de sus uersos cantando encantaron el mundo, llenando los sentidos la vanidad de sus conceptos, y cegando la rrazón la falsedad de sus proposiciones. Andaba entre ellos la Fiçión y la Mentira, rrigorosos fiscales de sus escritos, que alguna celebrada diossa en ellos mostró el desen-

$23^{\circ}$ gaño no ser para diablo buena. Seguían los omicidas y tira[f. $4 \mathbf{l l}^{\mathbf{0}}$ ] nos, verdugos de $/$ sí mismos, bibiendo su sangre en pago de la ynnocente que derramaron; entre los cuales Erodes parecía

194. todo ] todos

201. cuántos ] quantos $>$ cuantos

204. valedor ] voledor

205. desengaños ] desenganos

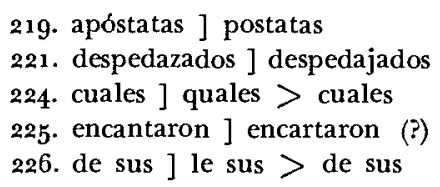

229. Es decir, en el día del Juicio (día del desengaño), se verá que muchas mujeres, mentirosamente celebradas como "diosas" por los poetas, no eran buenas ni para "diablos".

231. La forma bibiendo 'bebiendo' es análoga a quiriendo, cerimonia, etc. (cf. 
lastimadíssimo de auer uertido la que le condenó, sin llegar a la que le pudiera saluar.

Entró luego en mayor número que los dichos aquella peste común, enemiga ineuitable, Sensualidad: los trages, las galas, los afeytes, los hechizos, los embustes, y menos el ocio y la blandura, confusión de la rraçón y flaqueza de el ánimo, la bana sombra de la caduca hermosura, cuyas secas flores y

240 lisongeros alagos en infernales llamas y asquerosos tormentos se mostraban conuertidos: que era de uer los abrasados Leandros y ahogados Macías en uano y tarde arrepentidos del negro carbón que por oro de Arabia celebraron; las perlas, los rrubíes, las esmeraldas y rrosas, la niebe y grana, en poluo, en

245 humo, en sonbra y muerte rresueltos. ;Oh mentirosa condición de los honbres! ¡Quién bastara a persuadir vna verdad tan aprouada y mal seguida! QQuién a las damas deste siglo mostrara (aunque fuera en sueños) el christal del desengaño, donde el barniz perdiera la color y la voluntad mostrara sus 250 arrugas!

Tras la Sensualidad venía la Mentira y el Engaño, donde se me rrepresentó aquí el uerso de Dauid en el Salmo 67: "Increpa feras arundinis", etc. ¿Qué de plumas mal cortadas, qué de baras bien torcidas, qué de escribanos falsos, y quántos

255 juezes apasionados! ¡Cuántos pleytos injustos por culpa de abogados cudiciosos! ¡Qué de verdades muertas, y cuántas mentiras calificadas! iQué de rreos con premio, y cuántos inocentes condenados! Allí las marañas que cubrió el oro, la injusticia que olbidó el tiempo, los agrabios que disimuló el 260 fauor, en aquel cristalino desengaño se manifestaban con general tormento de los agresores. Y en éstos y en los demás delitos, que como infinitos no tienen modo para explicarse ni aun yo capacidad para compreenderlos, noté una cosa: que en día [de] tanta confusión no parecía aberla en nada,

233. le condenó ] se condeno

240. lisongeros ] lisongueros

242. Macías ] Macios

249. barniz ] baeniz (?)

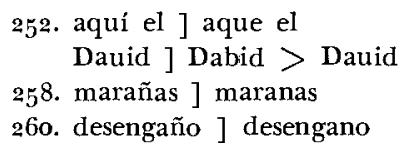

RAfael Lapesa, Historia de la lengua española, Madrid, 1955, p. 238). En la Politica de Dios de Quevedo (Madrid, ${ }_{1626}$ ) encuentro difinición, disinios, lición (fols. $10 \mathrm{v}^{\circ}$, $\left.20 \mathrm{r}^{\circ}, 78 \mathrm{r}^{\circ}\right)$. En el texto aquí publicado, cf. çimenterio, lín. 93.

249. Según el Dicc. Aut. (que aduce un ejemplo de Mateo Alemán), barniz es 'el baño o afeyte con que se componen el rostro las mugeres'.

252. También podría interpretarse "aquel uerso", pero me parece más sencilla y directa la lección "aquí el uerso".

253. Salmo $67: 3^{1}$.

263. La doble $e$ de compreender procede de la forma comprehender, frecuente en el siglo xvir, y empleada en el texto que aquí publicamos (supra, lín. I4I). Otros ejemplos de comprehender: Romera-Navarro, op. cit.; S. Denis, op. cit.; Sebastián de Covarrubias, Tesoro de la lengua castellana, ed. M. de Riquer, Barcelona, 1943; Dice. Aut., etc. Pero ya en 1693 Juan F. de Ayala Manrique declaraba que "lo ordinario y menos pesado es abreviar", diciendo comprender (cit. por GiLI GAYA, Tesoro, s. v. comprehender). 
265 pues los ministros infernales, con ser tan interessados en la [f. $44^{2} \mathrm{r}^{\circ}$ ] condenación | de aquellos miserables, sólo se occupaban en atormentarlos, [más] prosiguiendo en la possesión que aguardando la propiedad que con la final sentençia se les auía de dar de esas malditas almas, siendo cada vna en su particular

270 caussa testigo y parte, fiscal y juez. Que[dó] la sentençia del souerano aprouada, ante quien después de los rreferidos, pareció aquel descomulgado Apóstol que por tan poco preçio vendió la rredençión del mundo, como caudillo de otros tales que en la appariençia eran mansos corderos, siendo las entra-

275 ñas de hamvrientos y carniçeros lobos.

Allí la disimulada povreza mostró los tesoros mal allegados, el macilento color descubrió la sensualidad no creýda, las palabras manças y mortificadas vertieron ponzoña y crueldad, la apariençia engaño, el trato doble, y finalmente la virtud $\mathbf{2 8 0}$ ypocressía, pues todos, a imitaçión de su caudillo, que con besso de paz uendió al autor de ella a trueco de sus torpecas, lo hacían por momentos. Admiróme de suerte la nobedad de estos malditos ypócritas, que llebado della y de mi natural inclinaçión de sauer secretos no pensados, me entré tan aden-

285 tro que fue forzoso poner los ojos en el christal del desengaño, donde de inprouiso desbaneciendo las culpas agenas vi las mías tan manifiestas, que confusso y atemorizado de la grauedad de mis errores, con el nuebo assonbro me allé despierto -que la misericordia de Dios a uezes despierta en sueños a 290 los que velando duermen en el oluido de sus obligaciones.

265. interessados ] interrogados

273. rredençión ] rredepçion $>$ rredençion 278. ponzoña ] ponzona 285. en ] el $>$ en
286. agenas ] aguenas 287. confusso ] confiesso 288. assonbro ] aisonbro (?)

287. El copista escribió confiesso, quizá porque una $u$ mal hecha le pareció $i e$ (con poca abertura de la $e$ y sin punto en la i). Cf. supra, nota a la lin. 49 , y las letras de la fotografía citadas en esa nota. 